\title{
REINTERPRESTASI MAKNA RUANG JALAN LINGKUNGAN DI PERMUKIMAN PADAT PENDUDUK
}

\author{
Nia Suryani ${ }^{1}$, Fery Mulya Pratama ${ }^{2}$, \\ ${ }^{1}$ Universitas Indraprasta PGRI, Program Studi Arsitektur \\ niasuwardi@gmail.com \\ ${ }^{2}$ Universitas Indraprasta PGRI, Program Studi Arsitektur \\ pratama.ars@gmail.com
}

\begin{abstract}
Many social interactions occur in settlements that are already quite dense to become entertainment when people are tired inside the house. Social interaction activities that occur often cannot be conducive because often the road / gang cut in dense settlements is not more than 1.5 meters. Unwittingly this road has a dual function besides the circulation path as well as a place of interaction with the children's playroom which is vital for its effect on the quality of social life in this path. This research was conducted so that we as city designers can understand how public space can be interpreted according to the agreed functions, or if there is another meaning, it certainly becomes a predictable meaning of search results and handling
\end{abstract}

Key Words: alley, circulation, space of interaction, playground, dual function

\begin{abstract}
Abstrak : Banyak terjadi interaksi sosial di permukiman sudah cukup padat menjadi hiburan disaat warga penat di dalam rumah. Aktivitas interaksi sosial yang terjadi sering kali tak bisa terjadi secara kondusif karena sering kali lebar penggal jalan / gang di permukiman padat tidak lebih dari 1,5 meter harus berbagi dengan pengguna kendaraan bermotor yang berlalu lalang . Tanpa disadari jalan ini seolah memiliki fungsi ganda selain sebagai jalur sirkulasi juga sebagai wadah interaksi warga serta ruang bermain anak yang cukup vital pengaruhnya dalam kualitas kehidupan sosial dalam penggal jalan ini. Penelitian ini dilakukan agar kita sebagai perancang kota dapat memahami bagaimana sebuah ruang publik khususnya jalan dapat dimaknai sesuai fungsi yang direncanakan, ataupun seandainya terjadi pemaknaan lain, tentunya menjadi pemaknaan yang dapat diprediksi bagaimana akibat dan penanganannya.
\end{abstract}

Kata kunci : penggal jalan, sirkulasi, wadah interaksi, ruang bermain, fungsi ganda

\section{PENDAHULUAN}

Jalan lingkungan atau lebih dikenal sebagai gang sering menjadi tempat interaksi sosial manusia dalam kehidupan bertetangga. Interaksi sederhana sekedar menyapa saat berpapasan atau bahkan obrolan panjang kerap terjadi di penggal jalan ini. Banyak terjadi interaksi sosial di salah satu penggal jalan di kawasan lingkungan RT 04 RW 06 Cikiwul Bantargebang Bekasi ini karena permukiman sudah cukup padat dan didukung banyaknya istriistri yang tidak bekerja sehingga interaksi sosial ini bisa menjadi hiburan disaat penat di dalam rumah. Aktivitas interaksi sosial yang terjadi di penggal jalan ini cukup bervariasi, antara lain ibu-ibu yang bercengkrama, anak-anak bermain, ibu yang menyuapi balitanya, dan sebagainya.

Aktivitas interaksi sosial yang terjadi sering kali tak bisa terjadi secara kondusif karena dengan lebar jalan yang tidak lebih dari 1,5 meter harus berbagi dengan pengguna kendaraan bermotor yang berlalu lalang. Interaksi sosial ini masih dapat terjadi secara kondusif dan berlangsung agak lama di saat ada rumah warga yang memiliki teras sehingga aktivitas ini bisa terwadahi dengan 'aman'. Selain itu, penggal jalan ini pun seolah memiliki multipersepsi akan fungsinya bagi beberapa pengguna seperti pengendara motor dan sepeda, anak-anak, warga khususnya ibu-ibu yang mengunakan jalan ini sebagai ruang terbuka publik dengan peranan yang cukup penting. Fenomena di atas menggelitik rasa ingin tahu peneliti sebagai perancang kota (kawasan) tentang hal yang sebenarnya sering kita jumpai dalam keseharian.

Memandang penggal jalan ini sebagai jalan yang memiliki beberapa makna bagi penggunanya, sehingga timbul pertanyaan. Apa yang menyebabkan terjadinya pemaknaan berbeda pada fungsi ruang jalan ini? Dan apa yang mempengaruhi pemaknaan dari seseorang tentang fungsi ruang jalan ini?

Penelitian ini dilakukan agar kita sebagai perancang kota dapat memahami bagaimana sebuah ruang publik khususnya jalan dapat dimaknai sesuai fungsi yang direncanakan, ataupun seandainya terjadi pemaknaan lain, 
tentunya menjadi pemaknaan yang dapat diprediksi bagaimana akibat dan penanganannya.

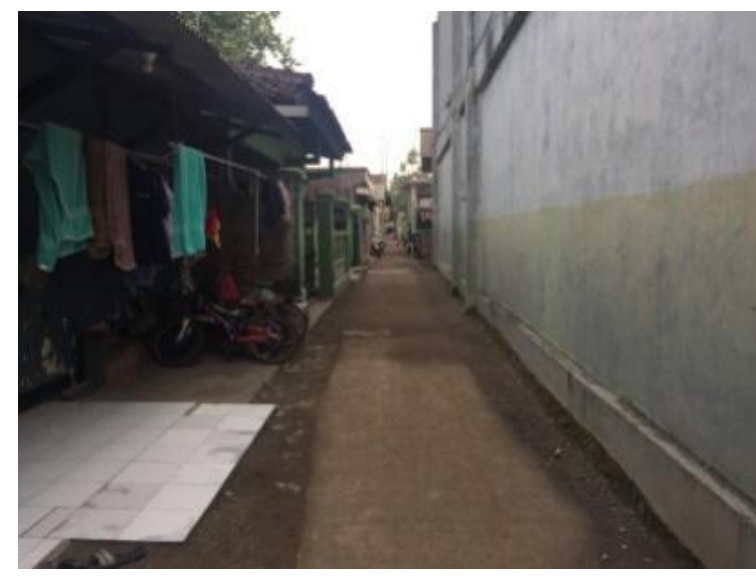

Gambar 1. Suasana penggal jalan saat tidak ada aktivitas

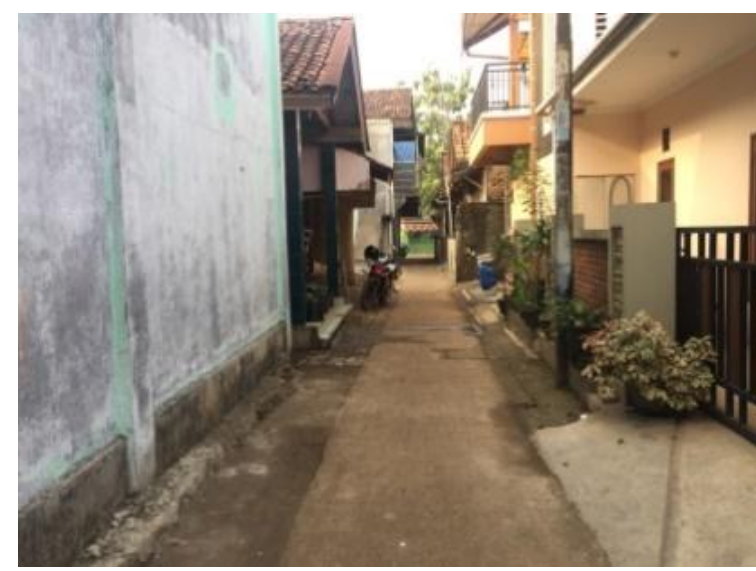

Gambar 2. Suasana penggal jalan saat tidak ada aktivitas

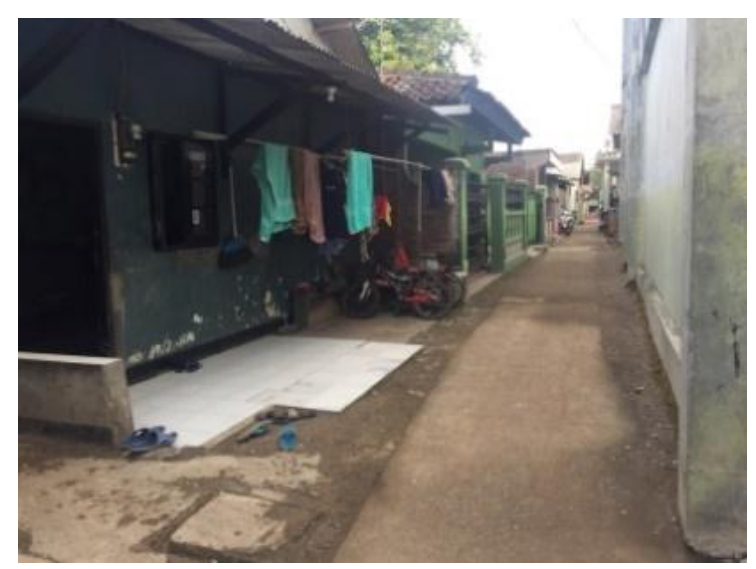

Gambar 3. Suasana penggal jalan saat tidak ada aktivitas

\section{METODOLOGI}

Metode yang dilakukan sebagai langkah dalam pencarian data dalam penelitian ini adalah metode kualitatif dengan pengamatan langsung yang diuraikan dalam pemetaan sederhana. Pemetaan dilakukan agar peneliti memahami bagaimana setiap pengguna jalan dapat menunjukan kecenderungan pemaknaannya terhadap fungsi ruang jalan ini. Pemetaan dilakukan secara acak namun terbagi menjadi dua, yakni penghuni rumah di sekitar jalan (pengguna berkala) dan pengguna jalan yang bersifat sesekali (lalu-lalang). Sehingga pengguna jalan terbagi menjadi tiga kategori yakni pengendara motor dan sepeda, anak-anak, dan warga khususnya ibu-ibu yang sering berinteraksi di sekitaran jalan ini.

\section{HASIL DAN PEMBAHASAN}

Penggal jalan yang peneliti lihat lebih dekat adalah penggal jalan yang merupakan jalan lingkungan pada permukiman kampung yang cukup padat. Jalan 1,5 meter ini menghubungkan jalan yang setingkat lebih lebar yakni sekitar 3-4 meter (dua jalur kendaraan roda 4). Seperti dijelaskan pada bagian sebelumnya jalan ini terlihat tidak seperti jalan lain yang hanya berfungsi sebagai jalur sirkulasi kendaraan (pergerakan) namun juga memiliki makna lain di benak para penggunanya. Dalam hal ini peneliti membagi tiga kategori pengguna jalan yakni pengendara motor dan sepeda, anak-anak, dan ibu-ibu.

Jika melihat dari sudut pandang anakanak,jalan ini berfungsi sebagai tempat bermain bagi anak-anak. Bagi anak-anak fungsi lain dari jalan ini (kecuali untuk bermain)adalah hal yang mengganggu bagi mereka. Di saat mereka sedang bermain petak umpet, tiba-tiba ada motor yang melaju kencang, hal itu menjadi hambatan ruang yang mereka tidak kehendaki. Anak-anak lebih sering menggunakan jalan ini dari rentang pukul 13.00-18.00 (hari kerja) dan 07.00-18.00 (hari libur). Waktu sepanjang itu mereka isi dengan aktivitas bermain diselingi waktu beberapa saat untuk makan dan solat. Permainan yang dilakukan bermacam-macam, seperti petak umpet, ucing jongkok, bermain boa, bermain karet, dan lian-lain. Aktivitas yang mereka lakukan harus sejenak berhenti jika ada kendaraan yang melintas.

Peneliti juga mencoba melihat dari sisi pengguna lain, yakni pengguna kendaraan, baik motor ataupun sepeda. Bagi pengendara jalan ini hanyalah sebagai jalur pergerakan yang mengharuskan mereka melaju kencang karena mobilitas di daerah permukiman ini cukup tinggi. Rata-rata pengguna jalan ini berprofesi sebagai pekerja baik buruh pabrik, pedagang, ataupun tentara angkatan darat (lokasi yang berdekatan 
dengan asrama militer). Profesi ini menuntut mereka harus segera cepat sampai di tujuan. Sehingga kondisi jalan ini (difungsikan untuk beberapa kegiatan) menjadi hambatan yang sangat terasa bagi pengguna jalan walaupun mereka terliaht masih mentolelir namun tersirat wajah agak kesal. Arus pergerakan yang cukup cepat ini pun menimbulkan ancaman keselamatan khususnya bagi anak-anak sehingga pemerintah RT setempat membuat polisi tidur untuk sedikit memperlambat kecepatan kendaraan yang melaju.

Sementara bagi ibu-ibu, jalan ini menjadi tempat interaksi paling nyaman untuk bertukar informasi atau istilah yang sering digunakan adalah ngerumpi. Terkadang mereka dudukduduk di salah satu rumah dekat jalan yang memiliki teras namun tidak jarang mereka duduk di pinggir jalan berhadapan sambil mengobrol. Mereka bisa menghabiskan waktu 2-2,5 jam dengan waktu yang tidak tentu tapi sering kali di pagi dan sore hari dengan personil yang terus bertambah. Misal di awal ada Bu Gimin dengan $\mathrm{Bu}$ Dedi yang sedang asyik mengobrol, kemudia Mama Iyan datang, kemudian tidak lama Mama Winda datang dan seterusnya hingga bisa sampai 6-7 orang yang mengobrol di satu titik tersebut. Lalu lalang kendaraan tak terlalu mengganggu mereka karena mereka tidak menggunakan langsung jalan sebagai ruang interaksi namun hanya dipinggiran saja, walupun jika ada motor yang sedikit berisik, mereka harus mengulang pembicaraan karena suaranya tak terdengar.

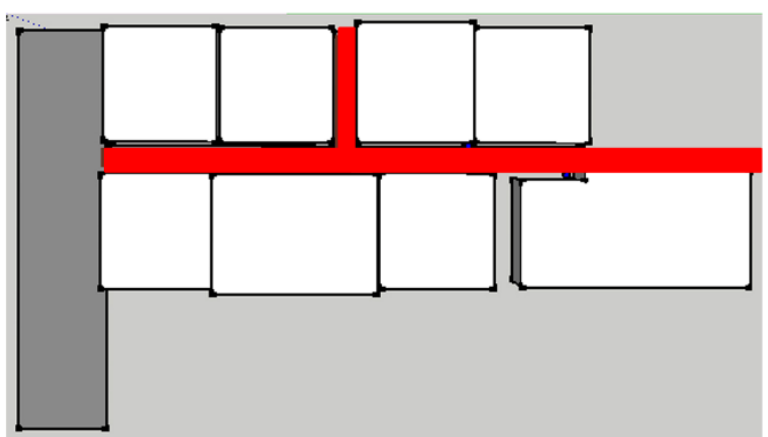

Gang RT 04 merupakan jalur perlintasan aktif bagi manusia dan kendaraan bermotor, yang juga sekaligus sebagai ruang bermain anak

Gambar 4. Sketsa Kondisi Eksisting Jalan

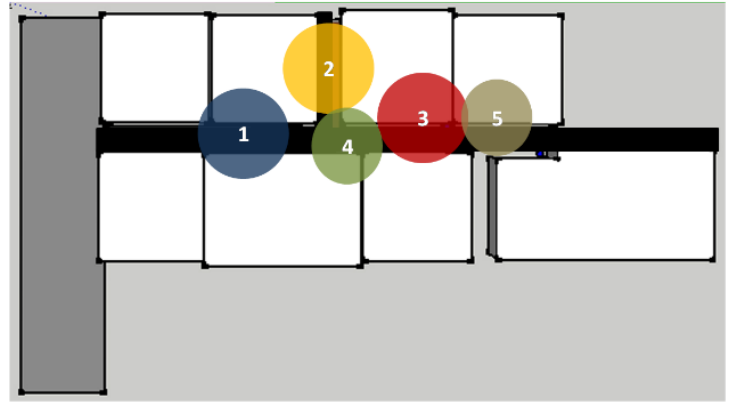

Berdasarkan pengamatan lapangan, lokasi no 1, 2 dan 3 merupakan titik lokasi tempat berkumpulny anak-anak untuk bermain di jalan. Sementara no 4 dan 5 merupakan titik berkumpulmya warga untuk

Gambar 5. Pemetaan Aktivitas Eksisting Ruang Jalan
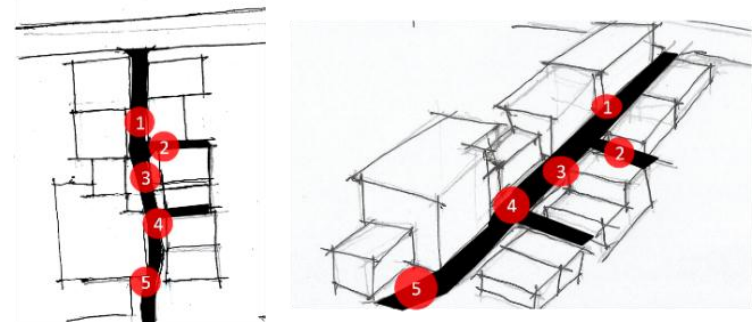

Berdasarkan pengamatan

no 1,2 dan 3

merupakan titik lokasi tempat
berkumpulnya anak-anak untulk

4 dan 5 merupakan titik.

4 dan 5 merupakan titik
berkumpulyya warga un

Gambar 6. Pemetaan Aktivitas Eksisting Ruang Jalan
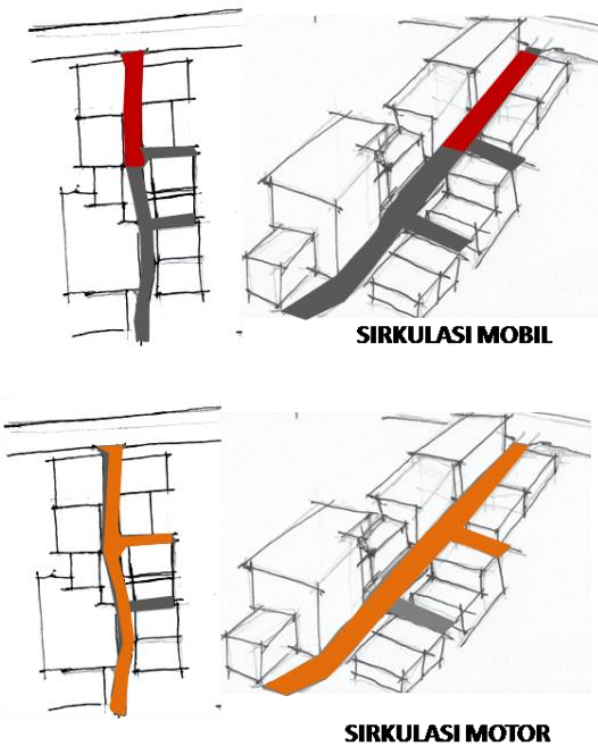

SIRKULASI MOTOR

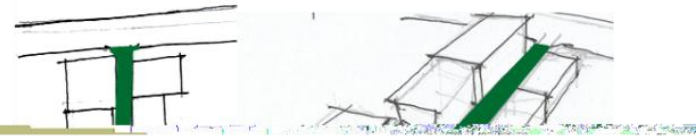

Gambar 7 . Pemetaan Sirkulasi Pengguna Ruang Jalan 

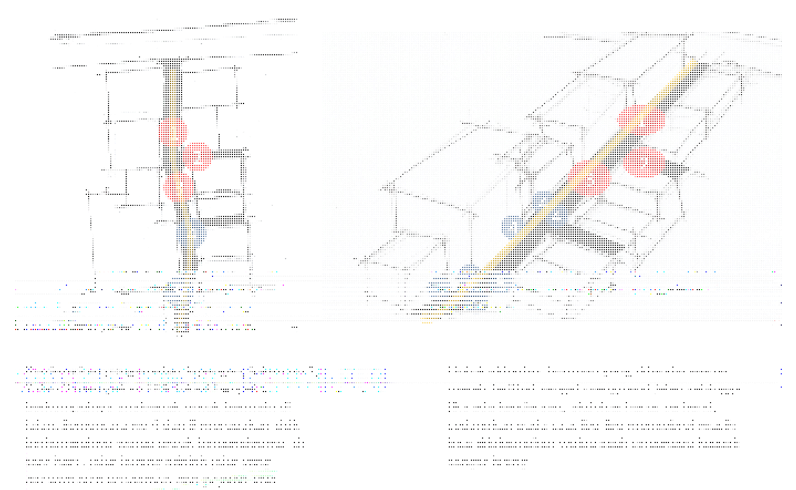

Gambar 8. Analisis Pemetaan Aktivitas Eksisting Ruang Jalan

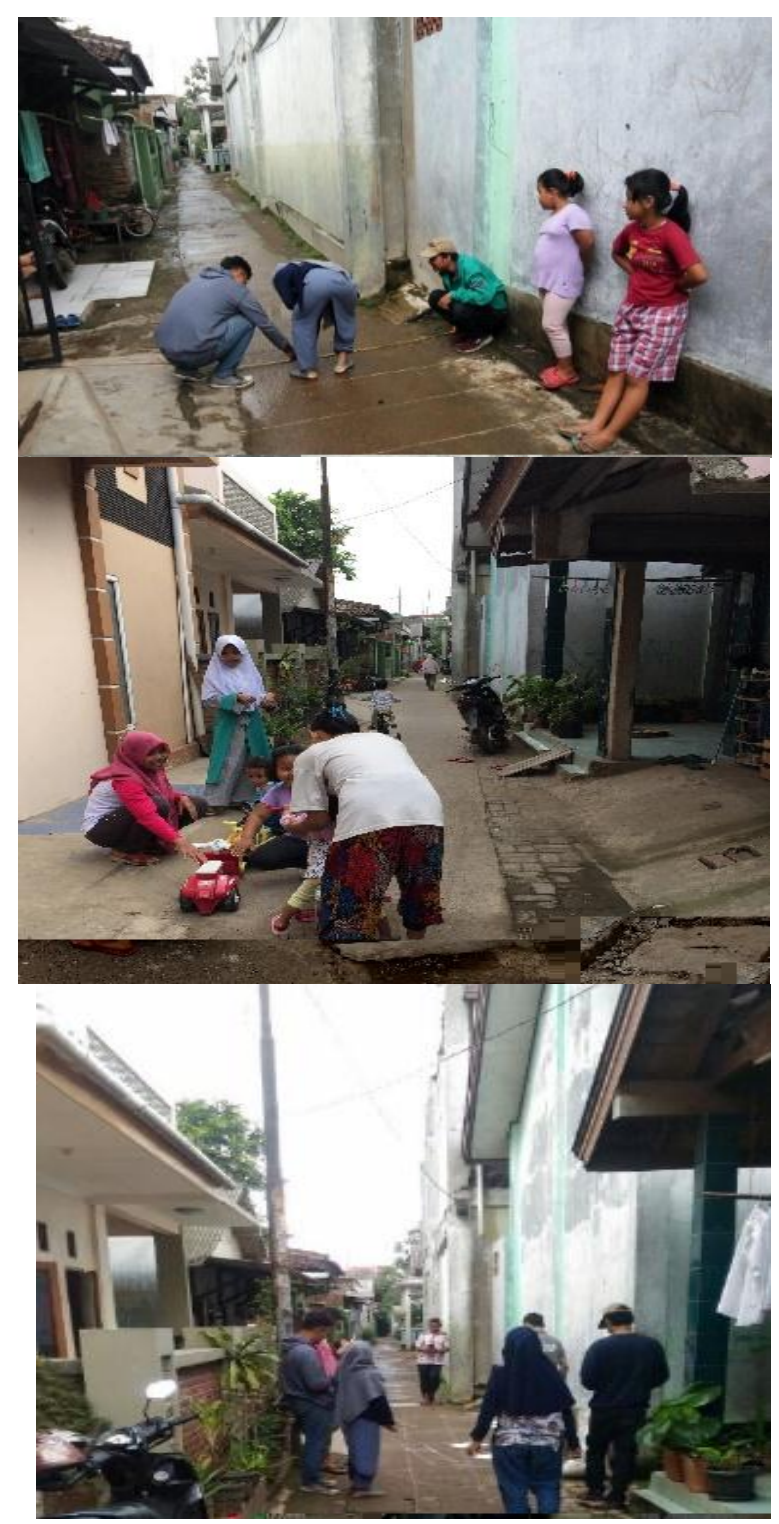

Gambar 9. Aktivitas Eksisting Ruang Jalan

\section{PENUTUP \\ Simpulan dan Saran}

Ruang jalan di lingkungan permukiman kampung dimaknai oleh para aktor sebagai jalur sirkulasi, sekaligus ruang terbuka publik. Ketiadaan ruang khusus, berkumpul, berekspresi, dan berinteraksi membuat para aktor memanfaatkan ruang di muka rumah sebagai ruang berinteraksi dan bermain anak. Berdasarkan kesepakatan antar aktor maka fungsi jalan sebagai jalur sirkulasi seringkali menjadi prioritas kedua karena sifat aktifitas anak di ruang jalan adalah penguasaan ruang. Aktifitas interaksi warga di sisi jalan juga membuat aktor yang melintas seperti tamu yang sedang "numpang lewat".

\section{DAFTAR PUSTAKA}

Darmawan, E. (2009). Analisa Ruang Publik Arsitektur Kota. Semarang: Badan Penerbit Universitas Diponegoro.

Lynch, K. (1960). The Image of The City. MIT Press. Madanipour, A. (1996). Design of Urban Space, An Inquiri into a Socio-Spatial Process. New York: John Wiley \& Sons.

Mulyandari, H. (2011). Pengantar Arsitektur Kota. Jakarta: Andi Publisher. Schulz, Christian Norberg. (1979). Genius Loci, Towards a Phenomenology of Architecture. New York: Rizzoli.

Mustikowati,E., Setioko,B., Syahbana,J. (2015). Faktor-faktor Penyebab Munculnya Activity Support di Kawasan Ruang Publik Bundaran Hotel Indonesia Jakarta Pusat. Teknik, 36(2), 68-74

Rigolon,A. (2013, Februari). Geomethodology Review : Behavioral Mapping. diunduh dari http://www.academia.edu/11525212/Geomet hodology Review Behavioral Mapping

Shirvani, Hamid. (1985). The Urban Design Process. New York: Van Nostrand Reinhold company, Inc.

Spreiregen, Paul. (1965). The Architecture of Towns and Cities. USA: Mc. Grawl Hill Companies. Trancik, Roger. (1986). Finding Lost Space. New York: Van Nostrand Reinhold Company.

Zahnd, Markus. (1999). Perancangan Kota Secara Terpadu. Yogyakarta: Kanisius.

Zumthor, P 2006, Atmospheres : Architectural Environment, Surrounding Objects, Birkhauser, University of California. 
74 Reinterprestasi Makna Ruang Ruang Jalan Lingkungan di Permukiman Padat Penduduk

Dawes, Michael J.2017. Christopher Alexander's A Pattern Language : Analysing, mapping, classifying the critical response. City, Territory and ArchitectureAn interdisciplinary debate on project perspectives

https://groupworksdeck.org/pattern-

language 